\title{
Effects of Size of Mix and Trituration Time on Physical Properties of Amalgam
}

\author{
by \\ Masayoshi OHASHI*, Fumio YAMAKI*, Masahide NIHEI*, \\ Motoharu MERA*, Kunio ODA*, Kiyoshi USUI*, \\ Tomikazu NISHIKAWA*, and Takeo SHIBAHARA*
}

\section{Introduction}

It is well known that the mercury-alloy ratio and trituration time greatly influence the physical properties of the amalgam, and there are a great number of studies about this. Nowadays, the standard approach to this problem is that the optimum trituration time varies according to the size of the mix, and trituration time should be extended as the size of mix increases. Reference books [1-2] and manufacturer's instructions on the use of alloys also advise the same approach. However, few stydies have been made to check the validity of this approach.

Recently, attention has been called to the fact that the trituration sound suddenly changes during mechanical trituration of an amalgam. The following report has appeared opposing the previously described established theory [3]: The time to sound change between the start of trituration and the point of sound change is shortened with the increase in the size of mix, indicating that the trituration time should be shortened as the volume increases. This report was also confirmed by a visual observation in the amalgam mix just after the point of soundchange and was in contradiction with the generally accepted theory.

In order to explicate which theory is true, the generally accepted theory or the new opposing theory, concerning correlation between size of mix and trituration time, the authors investigated this problem from the aspect of the physical properties of the amalgam. That is, for the purpose of reaching a correct conclusion, the experimental order was arranged at random statistically so that the relation between the size of mix and tirituration time could be analyzed in detail.

\section{Experimental Method}

Shofu Spherical alloys (Batch No. 234) were employed for this experiment as alloys, and triturated by Shofu mixer in a mercury-alloy ratio of 0.85 . For the trituration times, four different times, 5, 10, 20 and 30 seconds were chosen. The size of mix made from the $0.30 \mathrm{~g}$ minimum quantity of alloy and a fixed amount of mercury

*大橋正敬, 八巻文信, 仁平真佐秀, 米良根治, 小田邦雄, 臼井潔, 西川富一, 芝原健夫

Department of Dental Materials, Nihon University School of Dentistry, Tokyo, Japan 
was taken as 1 . In this study four different sizes of mix, 3, 4, 5 and 6 were adopted. The amount of triturated amalgam mix used for filling was always the same size as that of mix 3 and was filled in a mold with a diameter of $4.0 \mathrm{~mm}$ following the new "NON" filling method [4]. The length of the specimen was $8.0 \mathrm{~mm}$. Tensile and compressive strengths were determined after the elapse of 24 hours. The determination of tensile strength was based on the Diamietral Compressive Test [5-6], and dimensional change was determined by ADA specification [7].

\section{Experimental Results}

\subsection{Tensile strength}

Table 1 illustrates analysis of variance, and Fig. 1 the factorial effect of the size of mix and trituration time. In the table and figure, $*$ and $* *$ indicate a significant difference of $5 \%$ and $1 \%$, respectively, in the level of significance. No significant difference concerning the size of mix was recognized. However concerning the trituration time a significant difference was observed, and its percentage of contribution was $60.8 \%$. Upon examining the difference in tensile strength between

Table 1. Analysis of variance for tensile strength

\begin{tabular}{|c|c|c|c|c|c|c|}
\hline \multicolumn{2}{|c|}{ Source of variation } & \multirow{2}{*}{$\begin{array}{c}\mathrm{S} \\
2463\end{array}$} & \multirow{2}{*}{$\frac{\phi}{3}$} & \multirow{2}{*}{$\begin{array}{l}\mathrm{V} \\
821\end{array}$} & \multirow[t]{2}{*}{ Fo } & \multirow[t]{2}{*}{$\rho(\%)$} \\
\hline A: & Size of mix & & & & & \\
\hline $\mathrm{B}:$ & Trituration time & 72513 & 3 & 24171 & $17.0^{* *}$ & 60.8 \\
\hline $\mathrm{A} \times \mathrm{B}$ & & 5012 & 9 & 557 & & \\
\hline e: & Error & 32200 & 16 & 2012 & & \\
\hline (e): & Pooled error & (39675) & (28) & (1417) & & 39.2 \\
\hline $\mathrm{T}:$ & Total & 112188 & 31 & & & 100.0 \\
\hline
\end{tabular}

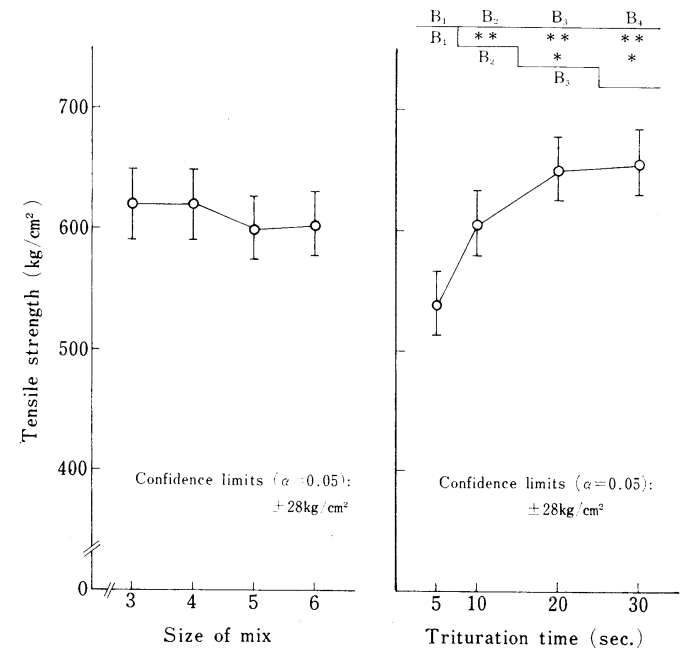

Fig. 1 Factorial effect on tensile strength 
amalgam mixs made at each level of trituration time, no significant difference in the trituration times between 20 and 30 seconds was recognized, however between the other combinations of times, a significant difference was noticed as illustrated in Fig. 1.

\subsection{Compressive strength}

Table 2 shows the analysis of variance and Fig. 2 the factorial effect of size of mix and trituration time. No significant difference in the size of mix was recognized. In trituration time, however, a significant difference of $1 \%$ was recognized in the level of significance and its percentage of contribution was $81.2 \%$. No significant difference was recognized in trituration time between 20 and 30 seconds; however, among the other combinations of times a significant difference was noticed.

Table 2. Analysis of variance for compressive strength

\begin{tabular}{|c|c|c|c|c|c|c|}
\hline & ource of variation & $\mathrm{S}$ & $\phi$ & $\mathrm{V}$ & Fo & $\rho(\%)$ \\
\hline A: & Size of mix & 18900 & 3 & 6300 & & \\
\hline $\mathrm{B}:$ & Trituration time & 1276300 & 3 & 425433 & $45.4 * *$ & 81.2 \\
\hline $\mathrm{A} \times \mathrm{B}$ & & 49600 & 9 & 5511 & & \\
\hline $\begin{array}{l}\text { e: } \\
\text { (e): }\end{array}$ & $\begin{array}{l}\text { Error } \\
\text { Pooled error }\end{array}$ & $\begin{array}{c}194000 \\
(262500)\end{array}$ & $\begin{array}{c}16 \\
(28)\end{array}$ & $\begin{array}{l}12125 \\
(9375)\end{array}$ & & 18.8 \\
\hline $\mathrm{T}:$ & Total & 1538800 & 31 & & & 100.0 \\
\hline
\end{tabular}
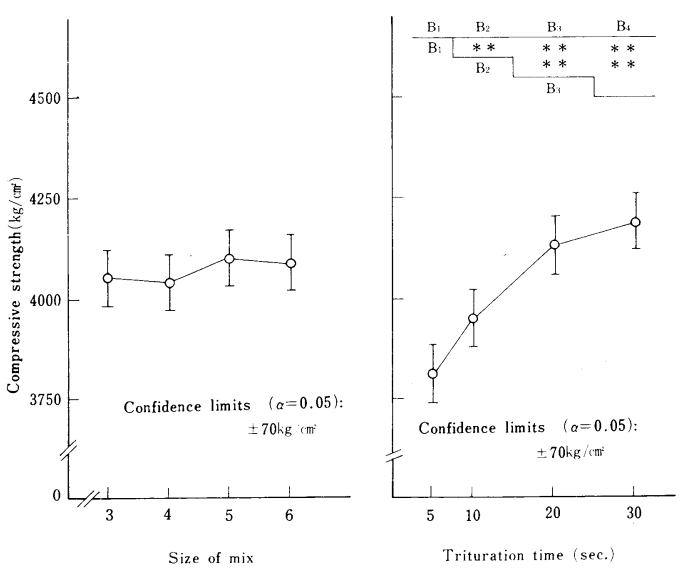

Fig. 2 Factorial effect on compressive strength of SS8

\subsection{Dimensional change}

Table 3 indicates analysis of variance and Fig. 3 the factorial effect of the size of mix and trituration tume. Here too, no significant difference concerning the size of mix was recognized; the same as in the previously described tensile and compressive strength tests. In trituration time, however, significant difference of $1 \%$ was observed in the level of significance and its percentage of contribution was $73.4 \%$. No significant difference was noticed in trituration time between 5 and 10 seconds; however, 
among the other combinations of times, a significant difference was recognized. In the case of 10 seconds or over, shrinkage increased significantly as trituration time was prolonged.

Table 3. Analysis of variance for dimensional change

\begin{tabular}{|c|c|c|c|c|c|c|}
\hline & urce of variation & $\mathrm{S}$ & $\phi$ & $\mathrm{V}$ & Fo & $\rho(\%)$ \\
\hline A: & Size of mix & 110 & 3 & 37 & & \\
\hline B: & Trituration time & 3367 & 3 & 1122 & $31.1 * *$ & 73.4 \\
\hline $\mathrm{A} \times \mathrm{B}$ & & 91 & 9 & 10 & & \\
\hline e: & Error & 811 & 16 & 51 & & \\
\hline$(\mathrm{e})$ : & Pooled error & $(1012)$ & $(28)$ & $(36)$ & & 26.6 \\
\hline $\mathrm{T}:$ & Total & 4379 & 31 & & & 100.0 \\
\hline
\end{tabular}

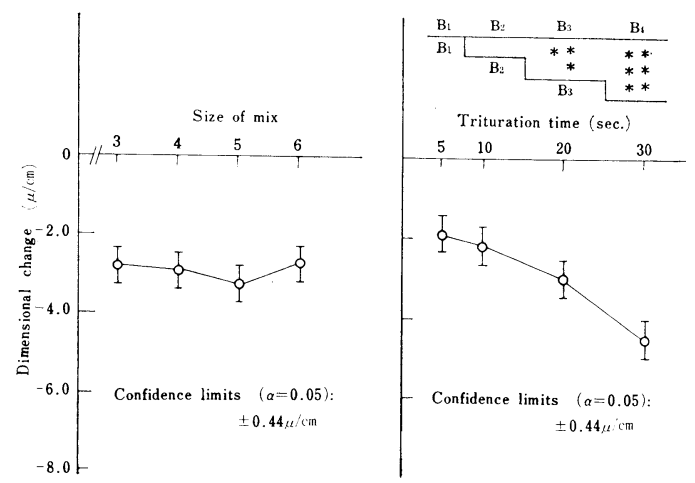

Fig. 3 Factorial effect on dimensional change of SS8

\subsection{The effect of the number of triturations}

In $3.1,3.2$ and 3.3 the effects of triturating different sizes of mix at a time was compared. In practice, however, when filling in large cavities, triturating the mix in separate smaller batches may be necessary. Therefore in this experiment, a fixed quantity of amalgam alloy $(0.90 \mathrm{~g})$ was mixed, separated into the following portions each of which was triturated for the indicated length of time, and its effect on tensile strength was compared:

$\mathrm{A} 1=0.90 \mathrm{~g}$ for 20 seconds (one trituration)

$\mathrm{A} 2=0.45 \mathrm{~g}$ for 20 seconds each (2 triturations)

$\mathrm{A} 3=0.30 \mathrm{~g}$ for 20 seconds each (3 triturations)

$\mathrm{A} 4=0.45 \mathrm{~g}$ for 10 seconds each (2 triturations)

$\mathrm{A} 5=0.30 \mathrm{~g}$ for 7 seconds each ( 3 triturations)

Table 4 shows the analysis of variance and Fig. 4 the factorial effect of the number of triturations. Significant effect of the number of triturations was recognized and the level of significance was $5 \%$. Among the levels, a significant difference was observed only in the combination between A5 and the other A1, A2 and A3, however, among 
the other combinations no significant difference was noticed. The tensile strength of A5 was the lowest of all the tests.

Table 4. Analysis of variance for effect of number of mix on tensile strength

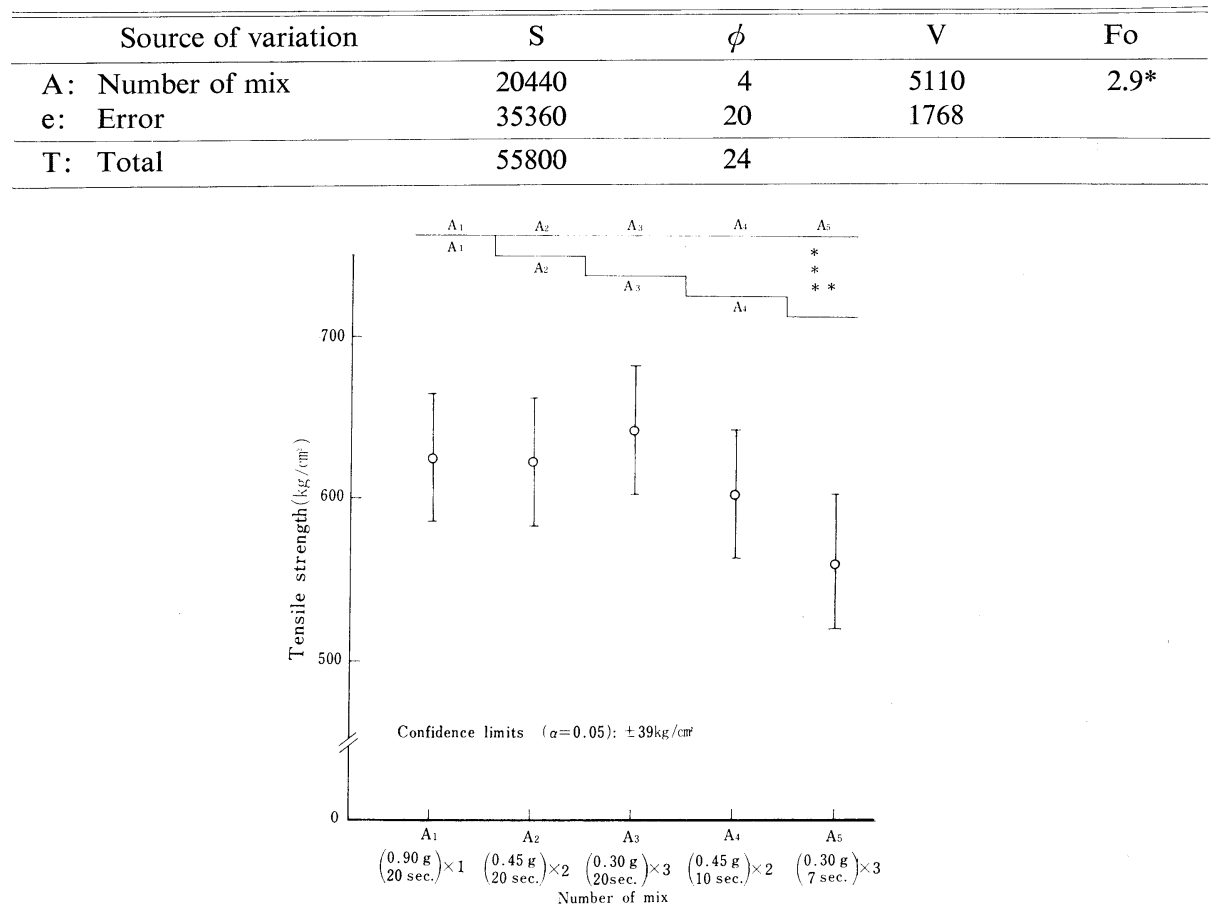

Fig. 4 Effect of number of mix on tensile strength

\section{Discussion}

The experimental results show that the size of mix has little effect on tensile and compressive strength, and dimensional change. But trituration time influences the above physical properties to a large extent; insufficient trituration time reduces the strength and too much trituration time increases shrinkage in dimensional change. This tendency agrees with many other reports [8-11]. That is, regardless of the size of the mix, only the amalgam which is mixed at the optimum trituration time cames out best.

It is generally considered that the more the size of the mix increases, the more the trituration time should be extended. And manuals of manufactureres give such instructions. However, it is clear from this investigation that the generally accepted theory is in the wrong.

Amalgam mix, when mixed in large sizes at a time, is left in the air for a long time before being used in filling and its strength declines [3, 8, 12]. It is generally believed, therefore, that an amalgam mix which is exposed to the air for three to three and half minutes or more after trituration, should be discarded, and a new 
amalgam mix should be triturated [1]. In such a case, therefore, the results of the experiment indicate that the amalgam should not be triturated all at once but separated into smaller batches to be triturated as needed. And variation in the trituration time is not necessary.

\section{Conclusion}

As a result of this comparative investigation on the relation between the size of mix and trituration time of the amalgam from the aspect of its physical properties using a statistical analysis, the following conclusion was obtained:

1) Change of trituration time has a considerable effect on the physical properties of amalgam. However, little influence was recognized by the change of the size of mix.

2) There is no need to change the optimum trituration time regardless of the size of mix or the number of trituration.

\section{References}

[1] Skinner, E. W. and Phillips, R. W.: The science of dental materials, 6th ed., W. B. Saunders Co., Philadelphia, 1967.

[2] Peyton, F. A.: Restorative dental materials, 3rd ed., The C. V. Mosby Co., Saint Louis, 1968.

[3] Nagai, K., Ohashi, M., Habu, H., Makino, K., Usui, T., Matsuo, M., Hama, M. and Kawaмото, М.: Effect of the mix size of amalgam on the triturating time, J. Nihon Univ. Sch. Dent., 12(4): 159-170, 1970.

[4] Nagai, K. and OHashi, M.: Three studies on a newly developed spherical amalgam in Japan and suggestions for its specification, J. Nihon Univ. Sch. Dent., 9(2): 43-48, 1967.

[5] Burns, C. and SweEney, W. T.: Application of the diametral compression test on dental materials, IADR progam and abstracts, p. 122, 1965.

[6] Nagai, K., Ohashi, M., Habu, H., Makino, K., Usui, T., Matsuo, M., Hama, M. and Kawaмото, M.: Studies on the tensile strength of dental amalgams by the application of diametral compression test. Part 2 Effects of manipulative variables, J. Nihon Univ. Sch. Dent., 13(1): 21-32, 1971.

[7] American Dental Association: Guide to dental materials, 2nd ed., American Dental Association, Chicago, 1964.

[8] Phillips, R. W.: Research on dental amalgam and its application in practice, J.A.D.A., 54: 309-318, 1957.

[9] WARD, M. L. and ScotT, E. O.: Effects of variations in manipulation on dimensional change, crushing strength and flow of amalgams, J. A. D. A., 19: 1683-1705, 1932.

[10] Caul, H. J., Lonton, R., Sweeney, W. T. and Paffenbarger, G. C.: Effect of rate loading, time of trituration and test temperature on compressive strength values of dental amalgam, J. A. D. A., 67: 670-678, 1963.

[11] Holst, K.: The influence of trituration time on the crushing strength of silver amalgam, Acta Odont. Scand., 23: 231-238, 1965.

[12] Jorgensen, K. D.: The effect of delayed condensation upon the crushing strength of amalgam, Acta Odont. Scand., 23: 271-275, 1965. 